\title{
Cognitive stimulations effects and Taigeiko in elderly women's cognition: an intervention
}

\author{
Efeitos de estímulos cognitivos e Taigeiko na cognição de idosas: uma intervenção
}

Los efectos de estímulos cognitivos y Taigeiko en la cognición de idosas: una intervención

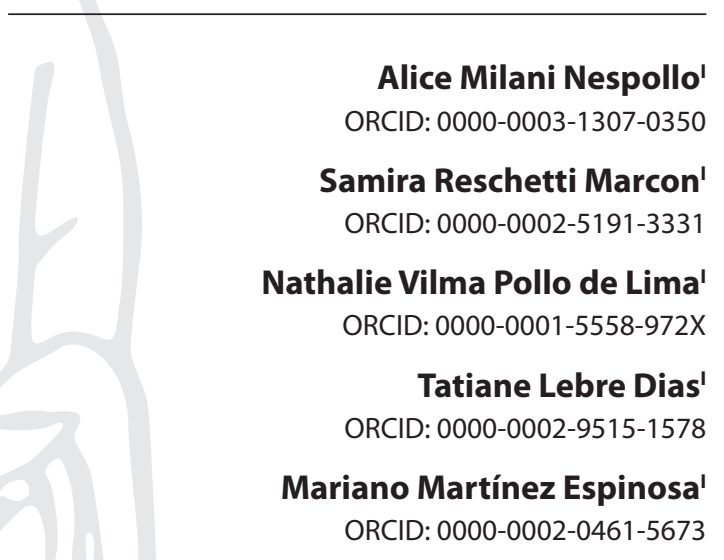

'Universidade Federal de Mato Grosso. Cuiabá, Mato Grosso, Brazil.

How to cite this article:

Nespollo AM, Marcon SR, Lima NVP, Dias TL, Espinosa MM. Cognitive stimulations effects and taigeiko in elderly women's cognition: an intervention.

Rev Bras Enferm. 2019;72(Suppl 2):79-87

doi: http://dx.doi.org/10.1590/0034-7167-2018-0133

Corresponding Author:

Alice Milani Nespollo

E-mail: alicenespollo@gmail.com

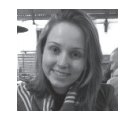

Submission: $03-03-2018$

Approval: 11-06-2018

\section{ABSTRACT}

Objective: To evaluate the effectiveness of an intervention through cognitive stimulation associated with Taigeiko practice in memory performance and executive function of elderly women, compared to a group exposed to Taigeiko alone. Method: A quasi-experimental study was performed with 16 elderly women. 10 were allocated to the experimental group (EG) submitted to 16 sessions of cognitive stimulation and Taigeiko, and 6 elderly women in the control group (CG) submitted to Taigeiko alone. Cognition was assessed before and after intervention by the tests: Rey Auditory-Verbal Learning (RAVLT); Rey-Osterrieth Complex Figure Test; Trail-Making Test; Stroop Effect; Digit Span Test and Semantic Verbal Fluency Test. Results: Both groups presented differences in RAVLT domains ( $E G \mathrm{p}=0.004, \mathrm{CG} p=0.005$ ) and Stroop Effect $(E G p=0.012 ; C G p=0.024)$. However, in $E G$, better scores were shown in the tests, although not statistically significant. Conclusion: Taigeiko has been shown to be a potential activity in obtaining cognitive gains, independently of the associated cognitive stimulation.

Descriptors: Aged; Cognition; Exercise; Neuropsychological Tests; Intervention Study.

\section{RESUMO}

Objetivo: Avaliar a efetividade de uma intervenção por meio de estímulos cognitivos associados à prática de Taigeiko no desempenho da memória e função executiva de idosas, comparado a um grupo exposto ao Taigeiko isoladamente. Método: Estudo quase-experimental com 16 idosas, sendo 10 alocadas no grupo experimental (GE) submetidas a 16 sessões de estimulação cognitiva e Taigeiko, e 6 idosas no grupo controle (GC) submetidas ao Taigeiko isoladamente. A cognição foi avaliada pré e pós-intervenção pelos testes: Aprendizagem Aditivo-Verbal de Rey (RAVLT); Figuras Complexas de Rey; Trilhas; Stroop; Span de Dígitos e Fluência Verbal Semântica. Resultados: Ambos os grupos apresentaram diferenças em domínios do RAVLT (GE $p=0,004 ; G C p=0,005$ ) e do Teste Stroop (GE $p=0,012 ; G C p=0,024$ ). No entanto, no GE foram evidenciados melhores escores nos testes, embora sem significância estatística. Conclusão: O Taigeiko demonstrou ser uma potencial atividade na obtenção de ganhos cognitivos, independente da estimulação cognitiva associada.

Descritores: Idoso; Cognição; Exercício; Testes Neuropsicológicos; Estudo de Intervenção.

\section{RESUMEN}

Objetivo: Evaluar la efectividad de una intervención por medio de estímulos cognitivos asociados a la práctica de Taigeiko en el desempeño de la memoria y función ejecutiva de ancianas, comparado a un grupo expuesto al Taigeiko aisladamente. Método: Estudio casi experimental con 16 ancianas, siendo 10 asignadas en el grupo experimental (GE) y sometidas a 16 sesiones de estimulación cognitiva y Taigeiko; y 6 ancianas en el grupo control (GC), sometidas al Taigeiko aisladamente. La cognición fue evaluada antes y después de la intervención por medio de las pruebas: Aprendizaje Aditivo-Verbal de Rey (RAVLT); Figuras Complejas de Rey; Rutas; Efecto Stroop; Span de Dígitos y Fluidez Verbal Semántica. Resultados: Los dos grupos presentaron diferencias en los dominios del RAVLT ( $G E p=0,004 ; G C p=0,005$ ) y en el Efecto Stroop (GE $p=0,012$; $G C p=0,024$ ). Sin embargo, en el GE se evidenciaron mejores puntuaciones en las pruebas, aunque sin significancia estadística. Conclusión: El Taigeiko demostró ser una potencial actividad en la obtención de ganados cognitivos, independientemente de la estimulación cognitiva asociada. Descriptores: Anciano; Cognición; Ejercicio; Pruebas Neuropsicológicas; Estudio de Intervención. 


\section{INTRODUCTION}

Aging is a worldwide event that has been occurring rapidly and progressively. This demographic transition is closely associated with an increase in the demand of health systems ${ }^{(1)}$, so that these services started to treat a greater number of specific diseases due to aging ${ }^{(2)}$, being cognitive decline an example of them.

Changes in brain structures are responsible for cognitive decline that may manifest as slowness in cognitive performance. With advancing age, some specific cognitive functions are more affected, such as the difficulty in remembering details and the tasks that will happen (memory ability); difficulty retrieving information already learned, as well as attention deficits (executive function) ${ }^{(3)}$.

The literature points out possible preventive factors for cognitive decline in the elderly, such as cognitive and physical activities, be they aerobic and resistance ${ }^{(4-5)}$. Such activities may be considered non-pharmacological therapies effective in protecting healthy cognitive status and slowing the rate of decline of already compromised cognitive functions ${ }^{(4)}$.

The isolated practice of the aforementioned activities is capable of inducing cerebral plasticity ${ }^{(3)}$, with significant improvement of cognitive status. However, recent studies propose that the combination of the two activities, either simultaneously or sequentially, is more effective in obtaining neural and cognitive benefits than when compared to independent performance ${ }^{(6-8)}$.

Oriental gymnastics and martial arts are considered physical and cognitive activities performed simultaneously, through standardized movements that have a higher level of complexity in relation to the repetitive movements of aerobic or resistance exercises $^{(9-11)}$. Thus, studies from the practice of Yoga ${ }^{(12-13)}$ and Tai Chi Chuan ${ }^{(14)}$, among others, demonstrate that these activities can provide considerable cognitive gains ${ }^{(11)}$.

Systematic review and meta-analysis studies with adults and older adults show that the practice of Yoga and Tai Chi Chuan are closely linked to moderate cognitive benefits ${ }^{(12)}$ and improvement in overall cognitive function ${ }^{(14)}$, respectively.

With roots attached to ancient Oriental physical fitness, such as Tai Chi Chuan, Yoga, Japanese Taizô and Chi Kung, Taigeiko (created by the Argentinean Federico Dinatale in the 90s, having been developed in Argentina, Spain and Brazil) is characterized as Oriental bioenergetic gymnastics that works on strength, flexibility and motor coordination. Taigeiko also works on bioenergetics, that is, the vital energy of the human being, besides involving physical, motor and mental aspects.

Because of Tai Chi Chuan and Yoga-inspired movements, which provide scientifically proven cognitive function improvement in healthy elderly ${ }^{(14-15)}$ and some kind of cognitive decline ${ }^{(16)}$, it is assumed that Taigeiko practice can exercise the same benefits. Considered a recent practice when compared to other Oriental arts, Taigeiko is still not widespread, thus, it is verified the inexistence of studies that investigate the possible relation between its practice and cognitive gains. Therefore, this statement is an important object to be investigated in order to fill this scientific gap.

It is noteworthy that, as far as the authors could demonstrate, there is a lack of studies that use the practice of martial arts associated with some type of cognitive activity, be it of stimulation, training or rehabilitation. Thus, there are few researches in the literature that investigate the development of these two activities and their repercussions.

\section{OBJECTIVE}

To verify if the isolated practice of Taigeiko promotes the improvement of memory performance and the executive function of elderly women. This study also compares the performance of memory and executive function of elderly women who participated in a cognitive stimulation associated with the practice of Taigeiko in relation to the group exposed to Taigeiko alone.

\section{METHOD}

\section{Ethical aspects}

This study was approved by the Research Ethics Committee of the Universidade Federal de Mato Grosso, Araguaia Campus, in accordance with Resolution 466/2012, which governs researches with human beings, guaranteeing anonymity to participants, as well as the free withdrawal of the study any time. Participants were invited to sign the Informed Consent Term for inclusion in the study.

\section{Design, place of study and period}

This is a quasi-experimental study, conducted at Universidade Federal do Mato Grosso, Cuiabá Campus, from February to July 2016.

\section{Population or sample: inclusion and exclusion criteria}

The population consisted of elderly women from Cuiabá-MT and districts, participants in the Extension Program "Healthy Longevity" developed by the Faculty of Physical Education of UFMT. This program is open to the community, includes participants over 60 years of both genders. The activities offered are dance classes, water aerobics, computers, among others. It has approximately 300 elderly people; in which women correspond to $95 \%$ of the population, a fact that determined the choice of the female in this study.

For sample selection, the inclusion criteria were: to participate for the first time in the "Healthy Longevity" Program; be female; be between 60 and 79 years old; have completed the initial years of elementary school education (first four years); to present results in the Mini-Mental State Examination (MMSE) ${ }^{(17)}$ above the cutoff point for education level; and present a result lower than five points in the Geriatric Depression Scale (GDS-15) ${ }^{(18)}$.

Exclusion criteria were: neurological antecedents (Cerebral Vascular Accident, seizures, epilepsy, Traumatic Brain Injury); make use of anxiolytic drugs, neuroleptics and/or antidepressants; present visual and/or visual limitations without corrective devices; difficulties in walking, use of walking aids, motor deficiency, sequel due to stroke and/or musculoskeletal diseases.

\section{Study protocol}

Recruitment occurred with dissemination of the study in local media and social networks, so that interested ones contacted by telephone with the researchers and scheduled the first interview that was held in the sports court at UFMT. Interviews were constituted in the first moment of the study, aiming to define participants according to the established criteria. Among the 41 elderly women evaluated by MMSE, GDS-15 and a sociodemographic, health and 
Activities of Daily Living questionnaire, two were excluded due to the use of antidepressants and anxiolytics, one due to depressive symptoms and five due to illiteracy, totaling 33 participants.

After participants'selection, in the second moment of the study, data collection with cognitive assessments started. These occurred individually at the UFMT Applied Psychology Service in an appropriate room with an approximate duration of one hour and evaluators trained and supervised by a UFMT teaching psychologist and researcher. At this stage, five elderly women were lost due to the withdrawal due to incompatibility of personal schedules and reasons, and in the end, the sample consisted of 28 participants. For neuropsychological assessment, six tests were widely used in studies with elderly individuals submitted to cognitive interventions, being they:

RAVLT: allows memory assessment through immediate memory skills, verbal learning, susceptibility to interference, being proactive or retroactive, retention of information after a period of time in execution of other activities and recognition memory. It consists of a list of 15 words (list A) read aloud and then an immediate recall (A1) test is performed. This procedure is repeated five times (A2, A3, A4 and $A 5)$ and in the sequence another list of words (list $B$ ) is read, by performing the recall test for this list (B1). After applying list $B$, the respondent is asked to recall the highest number of words from list $A(A 6)$. This process is repeated after an interval of 20 minutes (A7). Finally, a list of 50 words containing the words from list $A$ and list $B$, and 20 other words semantically or phonetically similar to the words from the previous lists, is presented, so that individual recognizes the words belonging to the first list. In this step, the recognition memory (REC) ${ }^{(19)}$.

Rey-Osterrieth Complex Figure Test: evaluates memory through the ability of visual memory and perception. A blank sheet is provided and a figure is displayed for the reviewer to copy. After 3 minutes after the end of the copy, the individual is asked to reproduce the same drawing, rescuing the figure from the memory in order to recover visual memory ${ }^{(20)}$.

Digit Span Test - WAIS-III: is able to evaluate attention, concentration and retention abilities of immediate memory in their direct order, and the working memory in the reverse order ${ }^{(21)}$, all of which belong to executive functions. It consists of a subtest of the Wechsler Adult Intelligence Scale. It is expected that individuals with healthy intelligence will be able to retain in the direct order at least five digits and in reverse order at least three digits ${ }^{(22)}$.

Trail-Making Test - Part A and B: through it, one can evaluate executive functions of attention, psychomotor speed, ability to perform and modify an action and ability to maintain two lines of thought, simultaneously. Composed in two parts, in part A is asked to draw lines that connect the numerical circles in numerical order, and in part B is asked that the individual connect numerical circles and letters alternately. The test execution is timed in seconds and assessment happens according to the time used ${ }^{(23)}$.

Stroop Effect: evaluates executive functions through selective attention, cognitive flexibility and susceptibility to interference ${ }^{(24)}$. It has numerous versions, all of which maintain the logic of the original test. In this study, the Victoria version was used, composed of three cards with 24 items, between squares, words and colors. On the first card, the participant is invited to speak the colors of the squares. Already in the second card, the participant must name the colors that the words are printed, being random words. On the third card, the participant must name the printed colors of the words consisting of color names, that is, ignore the written word and name the color of the print. Time is timed and errors are counted in each test phase ${ }^{(24)}$.

Semantic Verbal Fluency Test: it is able to evaluate the semantic memory and the processing of executive functions ${ }^{(24)}$. It consists of a quick and easy-to-apply test, where the respondent is asked to pronounce the largest number of animal names in a minute ${ }^{(25)}$.

The third moment occurred through allocation and formation of two groups, experimental and control, in a non-random manner, considering the availability for the development of the proposed activities.

Interventions were started with 14 participants in each group ( $4^{\text {th }}$ time). For EG the intervention consisted of 16 sessions of Taigeiko physical activity and cognitive stimulation. The two activities occurred on the same day and sequentially (Taigeiko and cognitive stimulation). The CG participated only in physical activity (Taigeiko), also completing 16 sessions.

Taigeiko sessions were taught by a qualified teacher and were based on the execution of activities from soft exercises and cardiovascular requirements, encompassing aerobic and anaerobic aspects lasting one hour for both the EG and CG.

Cognitive stimulation activities offered only to EG, also lasted one hour, and consisted of mathematical games, memory games, puzzles, crossbars, text interpretations, logical reasoning, among others. These activities were carried out with pencil and paper, aiming at a global stimulation of cognitive functions. The level of difficulty of both activities was gradually increased according to the progress of the sessions.

The activities were developed twice a week, totaling two months of intervention, with a minimum required frequency of 12 sessions (75\%). The definition of the maximum and minimum number of sessions was based on a systematic review study ${ }^{(6)}$ that proposes a minimum of 12 to 16 sessions of physical and cognitive training to obtain cognitive gains.

There were one drop out of the 28 women who started the study during follow-up, and two were excluded due to excessive absences, while in CG five they gave up and three were excluded due to absences, totaling 17 elderly women. Of those who completed the study, one was excluded because of failure to complete the instruments during the tests, resulting in 16 participants, 10 in the EG and 6 in the CG. With the end of the intervention, all the participants were re-evaluated with the same instruments ( $5^{\text {th }}$ moment).

\section{Analysis of results, and statistics}

Data collected were inserted into Microsoft Excel spreadsheets, later analyzed in the statistical program SPSS 17.0 and presented through tables. For descriptive analysis of the data, measures of central tendency (mean and median) and of variability/dispersion (Standard Deviation) were used. Data distribution was verified by the Shapiro Wilk Test. Therefore, for the inferential analysis, we used parametric and non-parametric tests according to the presented distribution. Pre and post-intervention comparisons in the same group (experimental or control) were performed from the paired t-test for dependent samples and the Wilcoxon Signed-Rank Test, while for comparisons between the groups with the different interventions, the Test $t$ paired for independent samples and the U-Mann Whitney Test. Significance level adopted was $\mathrm{p}<0.05$. 


\section{RESULTS}

The mean age for EG was 63.7 and for CG was 68.3 years. MMSE results, expressed as means, according to the groups, were 28.6 in the experimental group and 28.6 in the control group. In GDS-15, scores were 1.6 and 2.7 for EG and CG, respectively.

Regarding education level, the prevalent range was 11 years or more of formal education for both groups. As for occupational situation, for the two groups, the largest proportion was retired. When comparing sociodemographic variables of both groups, no statistical differences were found (Table 1).
Neuropsychological tests results applied before and after the end of the intervention for both groups are found in Table 2 and 3. EG presented significant differences in the variables "Total learning from List A of the RAVLT Test" and "Stroop Effect card first-reading time", while CG obtained difference in the variables "Late evocation of the RAVLT Test" and "Errors during reading of the Stroop Effects card two". There was no statistically significant difference between pre and posttest in the EG and CG for the Rey-Osterrieth Complex Figure Test, Digit Span Test, Trail-Making Test - part A and B and Semantic Verbal Fluency Test. There were also no significant differences between the types of interventions applied (Table 4).

Table 1 - Sociodemographic characteristics of the elderly participants of the study, according to the respective groups, Cuiabá, Mato Grosso, Brazil, 2016

\begin{tabular}{|c|c|c|c|c|c|}
\hline \multirow{2}{*}{ Variables } & \multicolumn{2}{|c|}{ Experimental Group $(n=10)$} & \multicolumn{2}{|c|}{ Control Group $(n=6)$} & \multirow[b]{2}{*}{$p$ value } \\
\hline & Mean $\pm S D$ & n (\%) & Mean士SD & n (\%) & \\
\hline Age & $63.70 \pm 3.40$ & & $68.33 \pm 6.80$ & & $0.171^{a}$ \\
\hline MMSE* $^{*}$ & $28.60 \pm 0.97$ & & $28.67 \pm 0.82$ & & $0.885^{a}$ \\
\hline GDS-15† & $1.60 \pm 1.26$ & & $2.67 \pm 1.37$ & & $0.155^{a}$ \\
\hline \multicolumn{6}{|l|}{ Education level } \\
\hline $1-4$ years & & $0(0.0)$ & & $2(33.3)$ & $0.125^{b}$ \\
\hline $5-8$ years & & $2(20.0)$ & & $0(0.0)$ & $0.500^{b}$ \\
\hline 9-10 year & & $2(20.0)$ & & $0(0.0)$ & $0.500^{b}$ \\
\hline$>11$ years & & $6(60.0)$ & & $4(66.7)$ & $1.000^{\mathrm{b}}$ \\
\hline \multicolumn{6}{|l|}{ Occupational situation } \\
\hline Retired & & $5(50.0)$ & & $4(66.6)$ & $0.633^{b}$ \\
\hline Working & & $4(40.0)$ & & $0(0.0)$ & $0.234^{b}$ \\
\hline Retired and working & & $1(10.0)$ & & $1(16.7)$ & $1.000^{\mathrm{b}}$ \\
\hline No occupation & & $0(0.0)$ & & $1(16.7)$ & $0.375^{b}$ \\
\hline
\end{tabular}

Note: *MMSE:Mini-Mental State Examination; TGDS-15: Abbreviated Geriatric Depression Scale. aStudent's TTest, for the difference between two means; bFisher's Exact Test for the difference between two means.

Table 2 - Comparison of pre and posttest of the elderly of Experimental Group, Cuiabá, Mato Grosso, Brazil, 2016

\begin{tabular}{|c|c|c|c|c|}
\hline \multirow[b]{2}{*}{ Variables } & \multicolumn{3}{|c|}{ Experimental Group $(n=10)$} & \multirow[b]{2}{*}{$p$ value } \\
\hline & $\begin{array}{c}\text { Pretest } \\
\text { Mean } \pm \text { SD }\end{array}$ & $\begin{array}{c}\text { Posttest } \\
\text { Mean } \pm \text { SD }\end{array}$ & Statistics & \\
\hline \multicolumn{5}{|l|}{ RAVLT$^{*}$} \\
\hline Immediate memory & $5.50 \pm 2.01$ & $7.20 \pm 1.93$ & $-2.18 \dagger$ & 0.058 \\
\hline List A Total & $39.50 \pm 9.61$ & $49.20 \pm 7.66$ & $-3.77 \dagger$ & 0.004 \\
\hline Total knowledge & $12.00 \pm 7.13$ & $13.20 \pm 5.39$ & $-0.29+$ & 0.779 \\
\hline Late evocation & $8.10 \pm 1.73$ & $9.80 \pm 2.82$ & $-1.90 \dagger$ & 0.090 \\
\hline Forgetting speed & $1.11 \pm 1.18$ & $1.00 \pm 0.16$ & $2.05+$ & 0.071 \\
\hline Recognition memory & $12.30 \pm 2.00$ & $13.30 \pm 1.42$ & $-1.59+$ & 0.146 \\
\hline \multicolumn{5}{|c|}{ Rey-Osterrieth Complex Figure Test } \\
\hline Copy total & $29.15 \pm 7.31$ & $31.80 \pm 2.90$ & $-1.26 \ddagger$ & 0.207 \\
\hline Copy time & $380.70 \pm 174.9$ & $347.50 \pm 190.40$ & $0.66 \dagger$ & 0.524 \\
\hline Memory total & $13.25 \pm 7.17$ & $17.15 \pm 7.90$ & $-2.21 \dagger$ & 0.055 \\
\hline Memory time & $215.40 \pm 114.5$ & $225.80 \pm 108.4$ & $-0.39+$ & 0.704 \\
\hline \multicolumn{5}{|l|}{ Digit Span Test } \\
\hline Direct & $8.20 \pm 1.55$ & $8.80 \pm 1.99$ & $-0.94 \dagger$ & 0.370 \\
\hline Inverse & $4.20 \pm 1.75$ & $5.00 \pm 1.76$ & $-1.56+$ & 0.153 \\
\hline \multicolumn{5}{|l|}{ Trail-Making Test } \\
\hline Part A time & $65.60 \pm 17.15$ & $60.70 \pm 23.88$ & $0.94 \dagger$ & 0.371 \\
\hline Part A error & $0.00 \pm 0.48$ & $0.00 \pm 0.00$ & $-1.73 \neq$ & 0.083 \\
\hline Part B time & $190.60 \pm 95.00$ & $151.60 \pm 67.7$ & $1.84 \dagger$ & 0.100 \\
\hline Part B error & $2.60 \pm 2.32$ & $0.90 \pm 0.87$ & $2.01+$ & 0.075 \\
\hline \multicolumn{5}{|l|}{ Stroop Effect } \\
\hline Card 1 time & $37.00 \pm 19.91$ & $22.00 \pm 4.90$ & $-2.50 \neq$ & 0.012 \\
\hline Card 1 error & $0.20 \pm 0.63$ & $0.20 \pm 0.63$ & $0.00 \dagger$ & 1.000 \\
\hline Card 2 time & $24.00 \pm 39.30$ & $24.10 \pm 4.63$ & $-1.24 \ddagger$ & 0.215 \\
\hline Card 2 error & $0.20 \pm 0.42$ & $0.40 \pm 0.521$ & $-1.00 \dagger$ & 0.343 \\
\hline Card 3 time & $53.30 \pm 55.6$ & $38.20 \pm 12.80$ & $-1.22 \ddagger$ & 0.221 \\
\hline Card 3 error & $1.00 \pm 1.05$ & $1.30 \pm 1.56$ & $-0.49+$ & 0.638 \\
\hline
\end{tabular}




\begin{tabular}{lccc}
\hline Variables & $\begin{array}{c}\text { Pretest } \\
\text { Mean } \pm \text { SD }\end{array}$ & $\begin{array}{c}\text { Experimental Group (n=10) } \\
\text { Posttest } \\
\text { Mean } \pm \text { SD }\end{array}$ & Statistics \\
\hline $\begin{array}{c}\text { Semantic Verbal Fluency Test } \\
\text { Score obtained }\end{array}$ & $16.70 \pm 4.60$ & $16.70 \pm 4.27$ & $0.00 \dagger$ \\
\hline
\end{tabular}

Note: *RAVLT: Rey Auditory-Verbal Learning; + Statistic: Comparison by paired t-test for dependent samples and pre and posttest values expressed as means; $¥$ Statistics: Comparison using the Wilcoxon Signed-Rank Test and pre and posttest values expressed in medians.

Table 3 - Comparison of pre and posttest of Control Group elderly women, Cuiabá, Mato Grosso, Brazil, 2016

\begin{tabular}{|c|c|c|c|c|}
\hline \multirow[b]{2}{*}{ Variables } & \multicolumn{3}{|c|}{ Control Group $(n=6)$} & \multirow[b]{2}{*}{$p$ value } \\
\hline & $\begin{array}{c}\text { Pretest } \\
\text { Mean } \pm \text { SD }\end{array}$ & $\begin{array}{c}\text { Posttest } \\
\text { Mean } \pm \text { SD }\end{array}$ & Statistics & \\
\hline \multicolumn{5}{|l|}{ RAVLT* } \\
\hline Immediate memory & $5.50 \pm 1.64$ & $5.67 \pm 1.86$ & $-0.22 \dagger$ & 0.833 \\
\hline List A Total & $37.17 \pm 10.46$ & $43.00 \pm 7.40$ & $-1.75+$ & 0.141 \\
\hline Total knowledge & $9.67 \pm 7.34$ & $14.67 \pm 3.39$ & $-2.03+$ & 0.098 \\
\hline Late evocation & $6.33 \pm 2.25$ & $9.33 \pm 3.14$ & $-4.74 \dagger$ & 0.005 \\
\hline Forgetting speed & $1.03 \pm 0.22$ & $1.32 \pm 0.60$ & $-1.30 \dagger$ & 0.251 \\
\hline Recognition memory & $12.00 \pm 3.69$ & $14.17 \pm 0.98$ & $-1.31 \dagger$ & 0.247 \\
\hline \multicolumn{5}{|c|}{ Rey-Osterrieth Complex Figure Test } \\
\hline Copy total & $30.92 \pm 34.36$ & $32.25 \pm 2.86$ & $-1.32 \dagger$ & 0.246 \\
\hline Copy time & $329.50 \pm 71.5$ & $324.50 \pm 162.90$ & $-0.73 \neq$ & 0.463 \\
\hline Memory total & $12.08 \pm 3.72$ & $11.17 \pm 5.07$ & $0.65+$ & 0.546 \\
\hline Memory time & $211.00 \pm 143.00$ & $267.0 \pm 273.00$ & $-0.73 \neq$ & 0.463 \\
\hline \multicolumn{5}{|l|}{ Digit Span Test } \\
\hline Direct & $8.00 \pm 2.45$ & $7.17 \pm 1.47$ & $1.19+$ & 0.289 \\
\hline Inverse & $4.66 \pm 1.66$ & $3.83 \pm 1.83$ & $1.19+$ & 0.289 \\
\hline \multicolumn{5}{|l|}{ Trail-Making Test } \\
\hline Part A time & $65.83 \pm 18.64$ & $53.83 \pm 23.18$ & $1.01+$ & 0.360 \\
\hline Part A error & $0.17 \pm 0.41$ & $0.33 \pm 0.51$ & $-0.54 \dagger$ & 0.611 \\
\hline Part B time & $181.5 \pm 92.8$ & $175.00 \pm 105.6$ & $0.27 \dagger$ & 0.798 \\
\hline Part B error & $1.33 \pm 1.03$ & $2.000 \pm 1.26$ & $-1.00 \dagger$ & 0.363 \\
\hline \multicolumn{5}{|l|}{ Stroop Effect } \\
\hline Card 1 time & $29.50 \pm 14.34$ & $25.67 \pm 5.82$ & $0.59+$ & 0.581 \\
\hline Card 1 error & $2.17 \pm 3.71$ & $0.50 \pm 1.22$ & $1.13+$ & 0.310 \\
\hline Card 2 time & $31.67 \pm 2.50$ & $28.67 \pm 9.22$ & $-0.95 \neq$ & 0.344 \\
\hline Card 2 error & $2.83 \pm 2.56$ & $0.33 \pm 0.81$ & $-2.26 \neq$ & 0.024 \\
\hline Card 3 time & $42.00 \pm 7.40$ & $43.67 \pm 7.87$ & $-0.59+$ & 0.582 \\
\hline Card 3 error & $5.67 \pm 4.50$ & $1.67 \pm 1.51$ & $2.21+$ & 0.078 \\
\hline \multicolumn{5}{|c|}{ Semantic Verbal Fluency Test } \\
\hline Score obtained & $16.83 \pm 2.86$ & $18.17 \pm 3.87$ & $-0.65 \dagger$ & 0.543 \\
\hline
\end{tabular}

Note: *RAVLT: Rey Auditory-Verbal Learning; + Statistic: Comparison by paired t-test for dependent samples and pre and posttest values expressed as means; $¥$ Statistics: Comparison using the Wilcoxon Signed-Rank Test and pre and posttest values expressed in medians.

Table 4 - Comparison between Experimental Group and Control Group, Cuiabá, Mato Grosso, Brazil, 2016

\begin{tabular}{lcccc}
\hline Variables & $\begin{array}{c}\text { Posttest } \\
\text { Experimental Group } \\
(\mathbf{n = 1 0 )}\end{array}$ & $\begin{array}{c}\text { Control Group } \\
(\mathbf{n = 0 6})\end{array}$ & Statistics & \\
\hline RAVLT* & & & & \\
Immediate memory & $7.20 \pm 1.93$ & $5.67 \pm 1.86$ & $1.57 \dagger$ & 0.147 \\
List A Total & $49.20 \pm 7.66$ & $43.00 \pm 7.40$ & $1.60 \dagger$ & 0.140 \\
Total knowledge & $13.20 \pm 5.39$ & $14.67 \pm 3.39$ & $-0.67 \dagger$ & 0.516 \\
Late evocation & $9.80 \pm 2.82$ & $9.33 \pm 3.14$ & $0.30 \dagger$ & 0.772 \\
Forgetting speed & $1.00 \pm 0.16$ & $1.32 \pm 0.60$ & $-1.24 \dagger$ & 0.270 \\
$\quad$ Recognition memory & $13.30 \pm 1.42$ & $14.17 \pm 0.98$ & $-1.23 \dagger$ & 0.240 \\
\hline
\end{tabular}




\begin{tabular}{|c|c|c|c|c|}
\hline \multirow[b]{2}{*}{ Variables } & \multicolumn{3}{|c|}{ Posttest } & \multirow[b]{2}{*}{ Posttest } \\
\hline & $\begin{array}{l}\text { Experimental Group } \\
\qquad(n=10)\end{array}$ & $\begin{array}{c}\text { Control Group } \\
(n=06)\end{array}$ & Statistics & \\
\hline \multicolumn{5}{|c|}{ Rey-Osterrieth Complex Figure Test } \\
\hline Copy total & $31.80 \pm 2.90$ & $32.25 \pm 2.86$ & $-0.30 \dagger$ & 0.768 \\
\hline Copy time & $347.50 \pm 190.40$ & $324.50 \pm 162.90$ & $-0.22 \neq$ & 0.828 \\
\hline Memory total & $17.15 \pm 7.90$ & $11.17 \pm 5.07$ & $1.85+$ & 0.088 \\
\hline Memory time & $225.80 \pm 108.4$ & $267.0 \pm 273.00$ & $-0.54 \ddagger$ & 0.588 \\
\hline \multicolumn{5}{|l|}{ Digit Span Test } \\
\hline Direct & $8.80 \pm 1.99$ & $7.17 \pm 1.47$ & $1.88 \dagger$ & 0.083 \\
\hline Inverse & $5.00 \pm 1.76$ & $3.83 \pm 1.83$ & $1.25+$ & 0.240 \\
\hline \multicolumn{5}{|l|}{ Trail-Making Test } \\
\hline Part A time & $60.70 \pm 23.88$ & $53.83 \pm 23.18$ & $0.57 \dagger$ & 0.583 \\
\hline Part A error & $0.00 \pm 0.00$ & $0.33 \pm 0.51$ & $-1.89 \neq$ & 0.590 \\
\hline Part B time & $151.60 \pm 67.7$ & $175.00 \pm 105.6$ & $-0.30 \dagger$ & 0.767 \\
\hline Part B error & $0.90 \pm 0.87$ & $2.000 \pm 1.26$ & $-1.88+$ & 0.103 \\
\hline \multicolumn{5}{|l|}{ Stroop Effect } \\
\hline Card 1 time & $22.00 \pm 4.90$ & $25.67 \pm 5.82$ & $-1.75 \neq$ & 0.080 \\
\hline Card 1 error & $0.20 \pm 0.63$ & $0.50 \pm 1.22$ & $-0.56 \dagger$ & 0.598 \\
\hline Card 2 time & $24.10 \pm 4.63$ & $28.67 \pm 9.22$ & $-1.48 \neq$ & 0.140 \\
\hline Card 2 error & $0.40 \pm 0.521$ & $0.33 \pm 0.81$ & $0.18 \dagger$ & 0.863 \\
\hline Card 3 time & $38.20 \pm 12.80$ & $43.67 \pm 7.87$ & $-1.36 \neq$ & 0.175 \\
\hline Card 3 error & $1.30 \pm 1.56$ & $1.67 \pm 1.51$ & $-0.68 \dagger$ & 0.510 \\
\hline \multicolumn{5}{|c|}{ Semantic Verbal Fluency Test } \\
\hline Score obtained & $16.70 \pm 4.27$ & $18.17 \pm 3.87$ & $-0.71 \dagger$ & 0.495 \\
\hline
\end{tabular}

Note: *RAVLT: Rey Auditory-Verbal Learning; + Statistic: Comparison by paired $t$-test for dependent samples and pre and posttest values expressed as means; $\neq$ Statistics: Comparison using the Wilcoxon Signed-Rank Test and pre and posttest values expressed in medians.

\section{DISCUSSION}

This study verified whether the isolated practice of Taigeiko promotes the improvement of memory performance and the executive function of the elderly women. It compared the performance of these functions in participants exposed to cognitive stimulation associated with physical exercises, in relation to a group that developed exclusively physical exercises.

In general, when analyzing the pre and posttest means of all the applied tests, in EG and CG, we perceive an improvement in the behavior of results, although few variables present statistical significance.

In $E G$, one of the variables that presented statistical significance was the "Total learning from List A of the RAVLTTest" and "Stroop Effect card first-reading time". These findings may predict that Taigeiko-based intervention associated with cognitive stimulation provided gains in memory, specifically in the ability to retain verbal memory and in executive function abilities (cognitive flexibility and selective attention).

A quasi-experimental study with 222 community elderlies in Australia compared performance on cognitive tests performed before and after the application of interventions in 80 sessions lasting 40-60 minutes. The groups were formed, according to the activities performed, being physical activity (aerobic and resistance), computerized cognitive activity, physical activity associated to cognitive and CG. This study results were of significant gains in the long-term verbal memory for the double intervention group in relation to the $\mathrm{CG}$, noting that for this measure, the cognitive test applied was the same used in the present study (RAVLT). For the isolated physical activity group, there were no statistically significant results for cognitive gains ${ }^{(26)}$.

With similar findings, a randomized clinical trial in the USA with 125 elderly stratified into four groups, similar to the previous study, divided into 48 sessions lasting 40 to 45 minutes, found significant gains for the variables of memory and executive function in the group of double intervention. In the isolated physical activity group, this study did not obtain significance ${ }^{(27)}$.

However, even though the differences between pre and posttest were not found for the same variables, this fact can be due to the difference in physical (aerobic ${ }^{(26-27)} \times$ Taigeiko) and cognitive (computerized ${ }^{(26-27)} x$ traditional). Results of this study are in agreement with the scientific literature, demonstrating that the association between physical and cognitive stimulation in the elderly may be more effective in obtaining neural and cognitive benefits than when compared to exercises, separately ${ }^{(6-8)}$.

It should also be noted that the CG, which performed only Taigeiko activity, gained gains in long-term verbal memory. CG was represented by the variable of late evocation in the RAVLTTest, and in the executive function abilities of cognitive flexibility and selective attention, through reduction of errors obtained during Stroop Effect second card reading. Unlike the physical intervention of aforementioned studies that developed up to five times more sessions of physical activities in relation to those performed in the present study, smaller number of sessions applied reinforces Taigeiko as a potential activity in obtaining cognitive gains, considering the results of improvement in memory and executive function. 
Other studies with elderly martial artists have shown that they can promote substantial gains in cognitive functions ${ }^{(9-11)}$. A study carried out in the Netherlands with 24 individuals aged 40 and over, who practiced for 15 months for one hour per week Taekwondo, found through cognitive assessments that after the intervention there was gain in the relative rate of inhibition and processing of information ${ }^{(11)}$. Another research carried out with the practice of Karate, compared to an aerobic exercise group and a CG, in Germany found that in the elderly with a mean age of 70 years martial arts practice proposed in the study for one hour, twice in the week for five months, was able to promote meaningful results in divided attention when compared to the other groups ${ }^{(10)}$.

It is interesting to note that both studies show gains in executive function skills, whereas in the present study, the significance is found in executive function and memory skills. This difference may be related to the essence of each of the martial arts mentioned here, since they have peculiarities. When comparing Taigeiko to randomized clinical trials and systematic reviews evaluating cognition through Tai Chi Chuan and Yoga practice, which are considered roots of the modality tested here, there are improvements in both executive and memory functions ${ }^{(12-14)}$, corroborating with the findings of this study.

Although no significant difference was found between the interventions performed, EG obtained an increase in the means of larger tests when compared to CG, a fact that may have occurred due to the potentiation of the physical and cognitive activity conjugation, as already mentioned previously. One hypothesis for the absence of statistical difference for some of the studied variables is the participants characteristics, since they had high schooling, controlled hypertensive disease, were extremely active and socially engaged, and used computers, cell phones, and activities with cognitive requirement, being these protective factors for cognitive decline $e^{(4-5)}$.

Thus, it is believed that for this sample of elderly women, intervention time was small, and activities performed were of low intensity, since for this group, there would be a need for a higher cognitive requirement for obtaining best results. In addition, EG performed two activities sequentially and although the literature points out gains with such a method, specifically in the participants of this study, there may have been cognitive fatigue and consequent lower gain. This finding may justify the variables in which the CG obtained better results after the intervention in relation to the EG. It should also be noted that the mean age and education level between EG and CG, although not statistically significant, may have influenced the results found. These findings reinforce the need for and feasibility of new studies with this population.

This research is innovative because as far as the authors could show there are no national or international studies that investigate the effectiveness of Taigeiko practice. This fact, coupled with positive results presented in the present research, demonstrates the need for continuity of investigation of cognitive aspects resulting from the practice of this modality. It is worth mentioning that the differential of the study is the association of Taigeiko, an activity with roots in martial arts, with cognitive stimulation, considering that the authors after extensive search in the literature did not find researches with this methodological approach.

\section{Study limitations}

Small number of study participants and non-randomization of the sample are limited, since, for these reasons, there is no possibility of generalization of the findings. Although the final number of participants was reduced during the segment of this research, comparing the findings of this research with international studies with larger samples reinforces the significance of results found and the need for new studies that use the same intervention methodology.

Another aspect to be emphasized is the difficulty of comparing the data. Research based on physical and cognitive interventions has important methodological differences such as the time of intervention, type and intensity of the exercises developed, frequency of activities, and the fact that physical and cognitive activities are sometimes developed simultaneously and in others, sequentially. This is reinforced by a systematic review investigating the influence of the combination of physical and cognitive exercises on the cognition of elderly individuals ${ }^{(6)}$.

\section{Contributions to the field of Nursing}

Considering the significant increase in the elderly population and the need for interventions that take into account clinical, pharmacological and non-pharmacological aspects, nursing plays a fundamental role as it develops the practice of care, seeking to fully meet the needs of the assisted population. Thus, studies with this type of methodological approach reaffirm the important role of nursing in the promotion of physical and mental health of elderly women as it provides activities that promote integration and moments of pleasure and well-being, in addition to being proven effective in cognitive improvement of this population.

\section{CONCLUSION}

Taigeiko has been shown to be a potential activity in obtaining cognitive gains. It can be evidenced in this study that, after the pre and posttest assessments, EG and CG obtained gains in memory and executive function, more specifically in the capacity of verbal memory retention, cognitive flexibility and selective attention for EG and in long-term verbal memory, cognitive flexibility and selective attention in CG. When comparing the types of interventions applied, EG obtained an increase in the means of tests greater than CG but without statistical significance.

\section{FUNDING}

This paper was carried out with the support of the Programa Nacional de Cooperação Acadêmica (Brazilian Program of Academic Cooperation) of the Coordination for Improvement of Higher Level Personnel - CAPES (Coordenação de Aperfeiçoamento de Pessoal de Nível Superior)/Brazil, Protocol 184100/PROCAD/2013. 


\section{REFERENCES}

1. Beard JR, Bloom DE. Towards a comprehensive public health response to population ageing. Lancet [Internet]. 2015 [cited 2017 May 2];385(9968):658-61. Available from: http://www.thelancet.com/pdfs/journals/lancet/PIIS0140-6736(14)61461-6.pdf

2. Veras R. Population aging today: demands, challenges and innovations. Rev Saúde Pública [Internet]. 2009 [cited 2017 Oct 2];43(3):548-54. Available from: http://www.scielo.br/pdf/rsp/v43n3/224.pdf

3. Bharer L. Cognitive plasticity in older adults: effects of cognitive training and physical exercise. Ann N Y Acad Sci[Internet]. 2015 [cited 2017 Sep 29];1337:1-6. Available from: http://onlinelibrary.wiley.com/doi/10.1111/nyas.12682/pdf

4. Alzheimer Disease International. World Alzheimer Report 2014: Dementia and Risk Reduction - an analysis of prospective and modifiable factors. [Internet]. London: Alzheimer Disease International; 2014 [cited 2017 Oct 21]. Available from: https://www.alz.co.uk/research/ WorldAlzheimerReport2014.pdf

5. Mangialasche F, Kivipelto M, Solomon A, Fratiglioni L. Dementia prevention: current epidemiological evidence and future perspective. Alzheimers Res Ther [Internet]. 2012 [cited 2017 Nov 10];4(6):1-8. Available from: https://www.ncbi.nlm.nih.gov/pmc/articles/PMC3471409/ pdf/alzrt104.pdf

6. Lauenroth $A$, loannidis $A E$, Teichmann B. Influence of combined physical and cognitive training on cognition: a systematic review. BMC Geriatr [Internet]. 2016 [cited 2018 Jan 9];16(141):1-14. Available from: http://bmcgeriatr.biomedcentral.com/articles/10.1186/ s12877-016-0315-1

7. Rahe J, Petrelli A, Kaesberg S, Fink GR, Kessler J, Kalbe E. Effects of cognitive training with additional physical activity compared to pure cognitive training in healthy older adults. Clin Interv Aging [Internet]. 2015 [cited 2017 Dec 2];10;297-310. Available from: https://www.ncbi. nlm.nih.gov/pmc/articles/PMC4304534/pdf/cia-10-297.pdf

8. Theill N, Schumacher V, Adelsberger R, Martin M, Jäncke L. Effects of simultaneously performed cognitive and physical training in older adults. BMC Neurosci[Internet]. 2013 [cited 2017 Jan 19];14(103):1-14. Available from: http://bmcneurosci.biomedcentral.com/ articles/10.1186/1471-2202-14-103

9. Douris $\mathrm{P}$, Douris $\mathrm{C}$, Balder N, LaCasse M, Rand A, Tarapore F, et al. Martial art training and cognitive performance in middle-aged adults. J Hum Kinet [Internet]. 2015 [cited 2017 Nov 17];47:277-283. Available from: https://www.ncbi.nlm.nih.gov/pmc/articles/PMC4633263/pdf/ jhk-47-277.pdf

10. Witte K, Kropf S, Darius S, Emmermacher P, Böckelmann I. Comparing the effectiveness of karate and fitness training on cognitive functioning in older adults: a randomized controlled trial. J Sport Health Sci [Internet]. 2015 [cited 2017 Nov 15];5(4):484-90. Available from: http://www.sciencedirect.com/science/article/pii/S2095254615000939

11. Pons Van Dijk GP, Huijts M, Lodder J. Cognition improvement in Taekwondo novices over 40: Results from the SEKWONDO Study. Front Aging Neurosci [Internet]. 2013 [cited 2017 Nov 3];5:1-5. Available from: https://www.ncbi.nlm.nih.gov/pmc/articles/PMC3822408/pdf/ fnagi-05-00074.pdf

12. Gothe PN, MCauley E. Yoga and cognition: a meta-analysis of chronic and acute effects. Psychosom Med [Internet]. 2015 [cited 2017 Nov 17];77(7):784-97. Available from: https://insights.ovid.com/pubmed?pmid=26186435

13. Nangia E, Malhotra R. Yoga, cognition and mental health. J Indian Acad Appl Psychol [Internet]. 2012 [cited 2017 Oct 20];38(2):262-9. Available from: http://jiaap.org/listing_detail/logo/cb13e18f-fc58-4f91-84fd-2993f7ef1 b84.pdf

14. Zheng G, Liu F, Li S, Huang M, Tao J, Chen L. Tai Chi and the protection of cognitive ability: a systematic review of prospective studies in health older adults. Am J Prev Med [Internet]. 2015 [cited 2017 Oct 9];49(1):89-97. Available from: https://www.ncbi.nlm.nih.gov/ pubmed/26094229

15. Guo Y, Shi H, Yu D, Qiu P. Health benefits of traditional Chinese sports and physical activity for older adults: a systematic review of evidence. J Sport Health Sci [Internet]. 2016 [cited 2018 Feb 18];5:270-80. Available from: https://www.sciencedirect.com/science/article/pii/ S2095254616300527

16. Siu M, Lee DTF. Effects of tai chi on cognition and instrumental activities of daily living in community dwelling older people with mild cognitive impairment. BMC Geriatrics [Internet]. 2018 [cited 2018 Mar 01];18-37. Available from: https://bmcgeriatr.biomedcentral.com/ articles/10.1186/s12877-018-0720-8

17. Bertolucci PHF, Brucki SMD, Campacci SR, Juliano Y. O mini-exame do estado mental em uma população geral: impacto da escolaridade. Arq Neuropsiquiatr [Internet]. 1994 [cited 2017 Oct 23];52(1):1-7. Available from: http://www.scielo.br/pdf/anp/v52n1/01.pdf

18. Paradela EMP, Lourenço RA, Veras RP. Validation of geriatric depression scale in a general outpatient clinic. Rev Saúde Pública [Internet]. 2005 [cited 2018 Jan 9];39(6):918-23. Available from: http://www.scielo.br/pdf/rsp/v39n6/en_26986.pdf

19. Malloy-Diniz LF, Lasmar VAP, Gazinelli LSR, Fuentes D, Salgado JV. The Rey Auditory-Verbal Learning Test: applicability for the Brazilian elderly population. Rev Bras Psiquiatr [Internet]. 2007 [cited 2017 Dec 7];29(4):324-9. Available from: http://www.scielo.br/pdf/rbp/v29n4/ a06v29n4.pdf

20. Oliveira MS, Rigoni MS. Figuras Complexas de Rey: teste de cópia e reprodução de memória de figuras geométricas complexas. $2^{\mathrm{a}}$ ed. São Paulo: Casa do Psicólogo; 2014. 141p. 
21. Souza LC, Teixeira AL. Rastreio cognitivo em idosos na prática clínica. In: Caixeta L, Teixeira AL, organizadores. Neuropsicologia Geriátrica. Porto Alegre: Artmed; 2014. p. 85-94.

22. Cunha JA. Psicodiagnóstico-R. Porto Alegre: Artes Médicas; 1993.

23. Salthouse TA. What cognitive abilities are involved in trail-making performance? Intelligence [Internet]. 2011 [cited 2017 Dec 5];39(4):22232. Available from: https://www.ncbi.nlm.nih.gov/pmc/articles/PMC3141679/pdf/nihms281938.pdf

24. Strauss E, Sherman EMS, Spreen O. A compendium of neuropsychological tests. 3a ed. New York: Oxford U Press; 2006.1240 p.

25. Brucki SMD, Malheiros SMF; Okamoto IH, Bertolucci PHF. Dados normativos para o teste de fluência verbal categoria animais em nosso meio. Arq Neuropsiquiatr [Internet]. 1997 [cited 2017 Oct 2];55(1):56-61. Available from: http://www.scielo.br/pdf/anp/v55n1/09.pdf

26. Shah T, Verdile G, Sohrabi H, Campbell A, Putland E, Cheetham C, et al. A combination of physical activity and computerized brain training improves verbal memory and increases cerebral glucose metabolism in the elderly. Transl Psychiatry [Internet]. 2014 [cited 2017 Oct 27];4(12):1-9. Available from: https://www.ncbi.nlm.nih.gov/pmc/articles/PMC4270308/pdf/tp2014122a.pdf

27. Shatil E. Does combined cognitive training and physical activity training enhance cognitive abilities more than either alone? a fourcondition randomized controlled trial among healthy older adults. Front Aging Neurosci [Internet]. 2013 [cited 2017 Nov 20];5(8):1-12. Available from: https://www.ncbi.nlm.nih.gov/pmc/articles/PMC3607803/pdf/fnagi-05-00008.pdf 